\title{
O ESTADO DA ARTE NA ARTICULAÇ̃̃O ENTRE OS TEMAS CULTURA ORGANIZACIONAL E INOVAÇÃOO
}

STATE OF THE ART IN THE RELATIONSHIP BETWEEN ORGANIZATIONAL CULTURE TOPICS AND INNOVATION

Recebido em 27.10.2014. Aprovado em 27.10.2015

Avaliado pelo sistema double blind review

Roberto Fabiano Fernandes

DOI: http://dx.doi.org/10.12712/rpca.v9i4.504

robertofabiano.fernandes@gmail.com

Universidade Federal de Santa Catarina (UFSC), Florianópolis/SC, BRASIL

\section{Dannyela da Cunha Lemos}

lemosda@gmail.com

Universidade do Estado de Santa Catarina (UESC), Florianópolis/SC, BRASIL

\section{Micheline Gaia Hoffmann}

michelinegaia@gmail.com

Universidade do Estado de Santa Catarina (UESC), Florianópolis/SC, BRASIL

\section{Simone Ghisi Feuerschütte}

ghisi.simone@gmail.com

Universidade do Estado de Santa Catarina (UESC), Florianópolis/SC, BRASIL

\section{Resumo}

Este trabalho objetivou caracterizar o estado da arte na produção acadêmica que articula os temas inovação e cultura organizacional sob um enfoque prescritivo, ou seja, as abordagens ou propostas voltadas ao gerenciamento da cultura com vistas à inovação. Além disso, ressalta-se que este trabalho segue uma abordagem qualitativa e que os resultados aqui apresentados fazem parte da etapa de pré-campo de um projeto de pesquisa chamado - Núcleo de Apoio a Gestão da Inovação. Para tanto, foi realizada uma revisão bibliográfica sistemática com bibliometria, com o propósito de investigar estudos que empregaram modelos/instrumentos de pesquisa predominantes na literatura, no sentido de confirmar as suas contribuições. Os resultados permitiram a elaboração de um portfólio de 22 artigos, dos quais sete tratavam do Competing Values Framework (CVF), de Cameron e Quinn (1999, 2006, 2011).

Palavras-chave: Inovação. Cultura Organizacional. Revisão Bibliográfica Sistemática.

\section{Abstract}

This study aimed to characterize the state of the art in academic research that articulates the themes innovation and organizational culture in a prescriptive approach, ie, approaches or proposals for managing the culture with a view to innovation. Furthermore, it is emphasized that this work follows a qualitative approach and the results presented here are part of the pre-field phase of a research project called - Core Support Innovation Management (NAGI). For this, a systematic literature review to bibliometrics, in order to investigate studies that used models / tools prevalent in the research literature, in order to confirm their contributions was performed. The results allowed the development of a portfolio of 22 items, seven of which dealt with the Competing Values Framework (CVF), Cameron and Quinn (1999, 2006, 2011).

Keywords: Organizational Culture. Systematic Literature Review. 


\section{Introdução}

A crescente importância atribuída ao tema inovação está associada a sua potencial relação com a performance organizacional em ambientes complexos e competitivos (NYBAKK; JENSSEN E INGE, 2012; CROSSAN; APAYDIN, 2010). A inovação possui uma dimensão de resultado que desperta interesse em organizações de diferentes naturezas, embora os conceitos originais tenham sido talhados no contexto industrial. Por outro lado, ela possui uma dimensão de processo envolvendo fatores que, associados, afetam a capacidade organizacional para inovar. (CROSSAN; APAYDIN, 2010; ISAKSEN; TIDD, 2006; SMITH et al., 2008).

Crossan e Apaydin (2010) realizaram uma revisão sistemática com o objetivo de construir um framework capaz de explicar os fatores determinantes da inovação. O resultado do trabalho ficou estruturado em três níveis: o nível do indivíduo e do grupo, em que o fator determinante da inovação é a liderança; o nível organizacional, em que os fatores determinantes são a estratégia, a estrutura e os sistemas, a alocação de recursos, a aprendizagem e gestão do conhecimento e a cultura; e o nível dos processos, composto pelos fatores tomada de decisão, gestão de portfólio, desenvolvimento e implantação, gestão de projetos e comercialização. Em uma abordagem similar, Smith et al. (2008) identificaram, a partir da análise de 102 estudos selecionados sobre o tema, 295 fatores que afetam a habilidade organizacional para gerenciar a inovação. Os autores sistematizaram os fatores identificados classificando-os em nove, quais sejam: tecnologia, processo de inovação, estratégia corporativa, estrutura organizacional, cultura organizacional, empregados, recursos, gestão do conhecimento e estilo de gerenciamento e liderança.

Como estes, vários estudos são consistentes ao apontar a cultura organizacional como um fator associado à capacidade de inovação. Como explicado por Isaksen e Tidd (2006), ela influencia o modo como as pessoas se comportam e como elas respondem ao imprevisto, à ambiguidade, à criatividade e à mudança. $\mathrm{O}$ trabalho de Smith et al. (2008), em particular, traz uma contribuição adicional associada ao fator cultura. Ele demonstrou que, além deste ser o fator mais citado na literatura, também é aquele que mais influencia a habilidade das organizações de gerenciar a inovação, na medida em que exerce o maior impacto sobre os demais fatores.
A cultura também é uma dimensão construída a partir das interações entre os membros e que se articula a todas as demais dimensões organizacionais. Nessa perspectiva, é possível dizer que as interações podem gerar círculos viciosos ou virtuosos para a inovação.

Assim, Isaksen e Tidd (2006) reconhecem que, embora a cultura seja um profundo, estável e complexo conjunto de suposições construídas ao longo do tempo e, por isso, difícil de ser modificada, ela é um dos fatores-chave a serem considerados quando o desafio em pauta é introduzir, gerenciar ou simplesmente compreender a mudança organizacional associada à inovação. Portanto, a conquista da inovação como um resultado que incrementa a performance organizacional envolve, entre outros fatores, o desenvolvimento de mecanismos para se gerenciar a cultura. Para isso, compreendê-la no âmbito de suas relações com a inovação pode ser um passo inicial.

No que diz respeito à articulação entre a dimensão cultural e a inovação sob o enfoque empírico e aplicado, ou seja, trabalhar a cultura organizacional com vistas à promoção da inovação, a literatura tende a delimitar e propor a intervenção sobre variáveis intervenientes ou mediadoras deste processo, como a ação do líder, por exemplo (ABDULLAHA et al., 2013). Esse tipo de delimitação, por vezes, pode não reconhecer a complexidade da dimensão cultural e as possibilidades de se gerenciar a sua relação com outras dimensões organizacionais direcionadas à inovação. Isaksen e Tidd (2006) alertam, a esse respeito, para as contribuições e armadilhas dos instrumentos de mensuração. Para os autores, nem sempre os dados já existentes ou as questões que são mais facilmente observadas são as mais relevantes ou as que deveriam ser mensuradas e consideradas como referencial para a intervenção. Nesse sentido, a escolha dos instrumentos se torna crucial.

Nessa perspectiva, o objetivo deste trabalho é caracterizar o estado da arte na produção acadêmica que articula os temas inovação e cultura organizacional sob um enfoque prescritivo, ou seja, as abordagens ou propostas voltadas ao gerenciamento da cultura com vistas à inovação. Adicionalmente, o trabalho analisa resultados de estudos que empregaram modelos/instrumentos de pesquisa predominantes na literatura, no sentido de verificar suas contribuições à temática.

O artigo está estruturado da seguinte forma: na próxima seção são apresentados os conceitos básicos 
de cultura organizacional e inovação que sustentaram o desenvolvimento do trabalho, seguidos, na terceira seção, da descrição dos procedimentos metodológicos. A quarta seção trata da apresentação dos resultados e da discussão abrangendo, primeiramente, a análise bibliométrica do portfólio de artigos - estado da arte - estudados; e, na segunda parte, a análise qualitativa de estudos que foram desenvolvidos com base em uma metodologia de gerenciamento da cultura organizacional identificada como predominante no estudo bibliométrico preliminar. Por fim, a quinta seção apresenta as considerações finais e aponta sugestões para futuras pesquisas sobre as temáticas trabalhadas neste artigo.

\section{Fundamentação teórica}

\section{Inovação e cultura organizacional}

O ambiente dinâmico e as transformações da realidade afetam o funcionamento das organizações de diferentes modos, em sua estrutura e em seus processos, pressionando-as a revê-los e a modificálos, bem como às suas interações e práticas simbólicas, em decorrência da necessidade de sobrevivência organizacional. Os processos de mudança, inerentes à vida das organizações, atingem diferentes dimensões - econômica, tecnológica, política, estrutural, social e humana - o que torna mais complexa a sua gestão e a busca pelo equilíbrio em todos os aspectos.

A despeito dos mecanismos utilizados para realizar mudanças, as organizações encontram-se submetidas às pressões ambientais que impõem a definição de estratégias e práticas inovadoras de adaptação às demandas que sustentam sua permanência em espaços competitivos e dinâmicos. $\mathrm{O}$ desenvolvimento tecnológico e as possibilidades infinitas de comunicação e informação forçam as organizações a buscarem alternativas para a inovação de seus recursos, produtos, processos, serviços e modos de produção, alterando a dinâmica das interações sociais e simbólicas construídas no contexto organizacional.

Para Birkinshaw, Hamel e Mol (2008) é a gestão da inovação, enquanto invenção e implementação de práticas, processos, estrutura ou técnicas, que promove $\mathrm{o}$ alcance mais efetivo das metas organizacionais. Os autores destacam que a inovação se constitui em mudança significativa para a vida da organização e, sendo assim, é possível que sua ocorrência afete dimensões subjetivas que orientam o funcionamento e as interações organizacionais, tais como a cultura e o comportamento dos seus integrantes.

De forma similar, com base em uma ampla revisão sistemática, Crossan e Apaydin (2010) conceituam inovação como a produção ou adoção, assimilação e aplicação de novos produtos, serviços, mercados, meios de produção ou métodos de gestão nas esferas econômica e social. Concluem que ela é, ao mesmo tempo, resultado e processo. Van de Ven, Angle e Poole (2000) apresentam abordagem similar. Do resultado, que corresponde a que tipo de inovação é desenvolvida e implementada, espera-se impacto sobre a performance e competitividade da firma, assim como sobre o desenvolvimento econômico do contexto em que ela está inserida (DAMANPOUR; SCHNEIDER, 2006). Dessa forma, inovação é algo novo que agrega valor ou riqueza (TIDD, BESSANT; PAVITT, 2008). O processo, por sua vez, envolve fatores determinantes da inovação, tais como liderança, estratégia, estrutura, alocação de recursos, aprendizagem e gestão do conhecimento e cultura organizacional (CROSSAN; APAYDIN, 2010; SMITH et al, 2008).

Assim, o processo que gera as inovações nas organizaçõesécomplexo, poisdependeintrinsecamente de elementos relacionados ao conhecimento que devem se traduzir em novos produtos e processos, inseridos em um ambiente que se caracteriza por mecanismos de feedback e interações envolvendo ciência, tecnologia, aprendizagem, produção, política e demanda (EDQUIST, 1997). O processo inovativo é fruto da coletividade, envolvendo portanto, múltiplos atores e desenvolvendo-se a partir das interações estabelecidas entre estes (CHESBROUGH, 2003; EDQUIST, 2007; ETZKOWITZ, 2011; TETHER, 2002; XERRI e BRUNETTOO, 2011). Além disso, é também um processo sistemático e não decorrente do acaso, que precisa ser institucionalizado e traz várias implicações do ponto de vista da cultura organizacional.

A explosão de estudos sobre a cultura organizacional ocorreu a partir da década de 1980, quando os pesquisadores perceberam que esta dimensão é uma forte influenciadora do comportamento de organizações, grupos e de indivíduos, interferindo na gestão interna das empresas bem como no modo como se relacionam e reagem às pressões ambientais. Apesar da constatação do forte papel que a cultura 
organizacional exerce sobre o funcionamento das organizações, esta dimensão tende a ser analisada muito mais no sentido da interpretação de suas expressões e significados do que em termos do seu gerenciamento (Pettigrew, 1979). Este aspecto é uma das discussões que tem sido focalizada quando se trata de estudos que relacionam a cultura com a dinâmica das mudanças nas organizações. Até que ponto a cultura da organização pode ser gerenciada? É possivel mudar a cultura de uma organização? (PETTIGREW, 1979; SCHEIN, 2009).

As respostas para tais questionamentos são sustentadas em fundamentos teóricos e epistemológicos de diferentes disciplinas que influenciaram os estudos sobre a cultura organizacional, tais como a antropologia, a sociologia e a psicologia. A abordagem interpretativa da cultura como um conjunto de padrões simbólicos e coletivos e compartilhados ao longo do tempo, por exemplo, é representativa de perspectivas teóricas da antropologia (BARBOSA, 2009).

Para Smircich (1983) as definições da cultura decorrem das formas como se entende o sentido e o papel desta dimensão no contexto organizacional. Fazendo uso de um recurso metafórico, a autora aponta que a cultura pode ser reconhecida, de um lado, como 'aquilo que a organização é' - ou seja, a organização é vista como um modelo simbólico de relacionamentos e significados (valores, crenças) construídos nos processos contínuos de interação entre os membros. Por outro lado, a cultura também pode ser entendida como 'o que a organização tem', uma variável organizacional a ser analisada em relação às interferências ambientais externas e aos aspectos internos que, em conjunto, definem o modo de ser e agir da organização, influenciando seus processos, estratégias e comportamentos em reação às demandas e pressões contextuais.

A cultura organizacional sob esta perspectiva, de acordo com Schein (2009), constitui um conjunto de pressupostos básicos, como valores e crenças e de padrões e modelos de funcionamento que a organização cria e desenvolve-por meio de seus grupos - para enfrentar problemas de adaptação externa e integração interna. Tais elementos são absorvidos ao longo do tempo pelos membros, transformando-se em referenciais para a ação à medida que se mostram válidos e compatíveis para responder e solucionar os referidos problemas.

A cultura se expressa e explica, portanto, o modo como os membros direcionam o seu dia-a-dia no trabalho, as suas formas de comunicação e as suas ações, bem como as regras, práticas e costumes que orientam a vida da organização (SCHEIN, 2009; TSENG, 2010). Considerando ser uma dimensão que se define com base na interação dos membros em torno de situações e exigências comuns, subjacentes ao contexto do trabalho e aos propósitos da organização, entende-se a cultura como uma construção social que deriva de um processo de aprendizagem coletiva (SCHEIN, 2009); processo este que permite a definição e a sustentação de ações planejadas e articuladas aos objetivos e às estratégias organizacionais, como as que focalizam a mudança e a inovação.

Em se tratando de um tipo específico de mudança, a taxa de inovação de uma organização é fortemente influenciada por sua cultura (NACINOVIC; GALETIC; CAVLEK, 2009). Da mesma forma, a cultura se mostra fundamental e precisa ser reconhecida no âmbito da gestão da inovação, considerandose que este tipo de mudança, a inovação, pressupõe aspectos diversos do funcionamento organizacional, da configuração estrutural aos padrões culturais que se consolidam - ou não - a partir das novas práticas (BIRKINSHAW; HAMEL; MOL, 2008).

De acordo com Dobni (2008), as organizações de sucesso absorvem a inovação em sua cultura e em sua forma de gestão, ou seja, têm a inovação como um valor organizacional. Valores como inovação e criatividade são comunicados e expressos na estrutura da organização, em suas políticas, artefatos, normas e práticas do dia a dia. Nesse sentido, a cultura de inovação é definida em sua multidimensionalidade e é contextual, abrangendo a configuração de valores, a infraestrutura, o apoio estratégico, a relação com o ambiente externo, os comportamentos necessários, além da intenção e do desejo da organização de assumir e agir sob o foco e na direção da inovação.

No que diz respeito aos estudos que associam a dimensão cultural e a inovação, até algum tempo privilegiaram a análise de elementos e padrões simbólicos ou de variáveis organizacionais relacionadas a tais dimensões. Dentre os elementos culturais estudados estão a liderança no processo da inovação (ABDULLAHA et al., 2013), os valores e as crenças, os padrões de comportamento e até a "marca" da organização, ou seja, as expressões visíveis da cultura - os artefatos culturais (SCHEIN, 2009).

Por outro lado, propostas de aplicação e de intervenção sobre a cultura organizacional para fomentar a inovação também foram identificadas na literatura. 
São modelos ou metodologias desenvolvidas a partir do estudo de contextos distintos e concebidas com base em fundamentos teóricos, tipologias e variáveis da cultura organizacional (CAMERON; QUINN, 1999, 2006, 2011; JONES et al., 2005). A despeito de suas especificidades, tais pesquisas e abordagens confluem para o reconhecimento da relevância de se gerenciar a cultura na direção da inovação (ASMAWI; MOHAN, 2011; DOBNI, 2008). Esta constatação desperta o interesse de se explorar propostas aplicadas de estudo da cultura organizacional e seu gerenciamento para a inovação, por meio de metodologias de análise, modelos ou ferramentas de intervenção.

Abdullaha et al (2013), por exemplo, desenvolveram um modelo a partir da análise da relação entre os valores da liderança e a cultura em uma população de sujeitos ligados a empresas do governo da Malásia. O propósito do estudo foi verificar como tais elementos culturais, os valores, afetam a inovação por meio da cultura organizacional. Fazendo uso de Modelagem de Equação Estrutural (SEM), os autores confirmaram a hipótese de que a cultura é um importante recurso para compreender como os valores de liderança e de inovação se relacionam, o que permite ao líder conduzir ações voltadas à criação de um ambiente que acolha e promova a inovação.

Já Asmawi e Mohan (2011), a partir da análise e identificação na literatura de fatores ou padrões culturais presentes nas organizações em geral, delinearam um modelo de análise da cultura organizacional para organizações de pesquisa e desenvolvimento (P\&D), onde a inovação se estabelece como princípio e como propósito. Os resultados da pesquisa revelaram oito fatores culturais associados àquele tipo de organização, quais sejam: o trabalho em equipe, o compartilhamento do conhecimento, a capacitação e reconhecimento, a conformidade e os limites da pesquisa e do desenvolvimento, o enfrentamento aos riscos, a orientação para o cliente, a autonomia, as redes sociais e o desenho organizacional. Esses fatores, que se pode entender como valores imbricados no funcionamento das referidas organizações, repercutem na forma de um modelo ou ferramenta para medir a cultura organizacional subjacente às organizações de $P \& D$, auxiliando os gestores em suas iniciativas e ações voltadas à inovação.

O desenvolvimento de um instrumento abrangente para medir a cultura da inovação foi o propósito do estudo de Dobni (2008). O autor estabeleceu um conjunto de descritores obtidos junto à literatura e, por meio de pesquisa empírica com profissionais de organizações financeiras, gerou uma escala estruturada em alguns fatores de análise para avaliar a cultura de inovação. São eles: a propensão para a inovação, o ciclo da inovação, a aprendizagem organizacional, a criatividade, a autonomia, a orientação para o mercado e a orientação de valor e o contexto de implementação.

Tal como já mencionado, as abordagens ou propostas aplicadas para relacionar a cultura e a inovação nas organizações se sustentam em perspectivas teóricas ou teórico-empíricas já consolidadas em torno de conceitos, tipologias e modelos de análise e mensuração da cultura organizacional. A análise bibliométrica que dá suporte ao presente trabalho identificou um conjunto de sete estudos aplicados e orientados pelo Competing Values Framework (CVF) de Cameron e Quinn (1999, 2006, 2011), o qual se revelou como o Modelo ou framework prevalecente nos estudos que tratam do gerenciamento da cultura para a inovação organizacional.

Os estudos selecionados com base no CVF foram desenvolvidos em contextos diversos e com propósitos distintos. Sua representação neste artigo tem em comum a exploração de fatores culturais abordados de modo empírico ou como objeto de análise e/ ou intervenção que, em última instância, interferem na compreensão sobre processos de mudança ou na promoção da inovação nas organizações estudadas (JONES; JIMMIESON; GRIFFITHS, 2005; ONEY-YAZICI et al, 2007; HARTNELL; OU; KINICKI, 2011; NARANJO-VALENCIA; JIMENEZ-JIMÉNEZ; SANZ-VALLE, 2011, 2012; BUSCHGENS; BAUSCH; BALKIN, 2013).

\section{O Competing Values Framework (CVF)}

O Competing Values Framework (CVF), de Cameron e Quinn (1999, 2006, 2011), foi elaborado a partir da visão dos autores sobre a necessidade de estudiosos, pesquisadores e praticantes de gestão de terem acesso a formas de gerenciamento da mudança da cultura organizacional, além de conhecer e saber elaborar análises sobre a cultura das organizações modernas.

Para os autores, a necessidade de mudança na cultura das organizações é correspondente à dinâmica e rapidez com que o ambiente tem se transformado e afetado o funcionamento e o desempenho organizacional a partir do século XX. Entendem que os 
administradores, agentes de mudança e pesquisadores precisam desenvolver habilidades de gerir o processo de mudança da cultura organizacional na direção da competitividade e, para isso, consolidaram o CVF, que propõe meios para diagnosticar e orientar a mudança da cultura organizacional. Trata-se de uma metodologia voltada à mudança cultural que contempla a transformação no nível do indivíduo, ou seja, um modelo que promove a mudança cultural articulada ao comportamento individual do gestor (CAMERON; QUINN, 2006).

A operacionalização do CVF ocorre com base na aplicação do Organizacional Culture Assessment Instrument (OCAI), que é o Instrumento de Avaliação da Cultura Organizacional. O instrumento é estruturado na forma de um questionário que permite ao pesquisador traçar um diagnóstico da cultura, abrangendo elementos a ela subjacentes, o que, segundo os autores, auxilia os membros a pensarem nos seus propósitos para o futuro diante das demandas e oportunidades apontadas para a empresa (CAMERON; QUINN, 2006, p. 23).

O diagnóstico da cultura organizacional elaborado a partir do OCAI contempla seis passos ou etapas que constituem dimensões abrangentes compostas, cada uma delas, por quatro variáveis/descritores que as caracterizam e serão indicadas pelos respondentes em uma escala analítica. A proposta do instrumento é que os gestores apontem, em relação aos descritores relacionados a cada dimensão contida no instrumento de diagnóstico, a sua percepção sobre o estado atual e o estado desejado para a organização.

As seis etapas/dimensões de análise definidas no $O C A I$ são: características dominantes na organização; liderança organizacional; gestão de pessoas; a "cola" (ou vínculo) na organização; a ênfase estratégica e; os critérios de sucesso da organização (CAMERON; QUINN, 2006, p. 23-31). Os resultados da aplicação do OCAI, ou seja, a análise das dimensões com suas respectivas variáveis irão consolidar o diagnóstico e permitir um conhecimento mais ampliado da organização, envolvendo o desenho organizacional, os estágios de desenvolvimento do ciclo de vida, os princípios e padrões de qualidade e a efetividade, o papel da liderança e dos gestores de recursos humanos e as habilidades de gestão.

Tendo como base os resultados de pesquisas os autores identificaram trinta e nove indicadores, os quais foram sistematizados e compuseram duas dimensões que diferenciam os critérios de efetividade organizacional. As dimensões estão estruturadas em polos/quadrantes opostos no modelo: a primeira enfatiza a análise da flexibilidade e a dinamismo de um lado, e a estabilidade e o controle, de outro, enquanto padrões de funcionamento da dinâmica organizacional. Já a segunda dimensão abrange critérios de efetividade baseados na orientação interna, integração e unidade organizacional em oposição à orientação externa, diferenciação e rivalidade em relação ao ambiente da organização (CAMERON; QUINN, 2006). As duas dimensões estabelecidas formam os quatro quadrantes do $C V F$ e de acordo com os autores, apontam indicadores que definem os valores centrais relacionados à performance e à efetividade organizacional.

O CVF sintetiza, portanto, valores e pressupostos opostos e concorrentes que servem de base para, analiticamente, caracterizar a cultura organizacional predominante através do contínuo entre flexibilidade e estabilidade e entre orientação interna e externa. A interação entre essas quatro dimensões deu origem aos quatro quadrantes que identificam as tipologias culturais apontadas por Cameron e Quinn (1999, 2006, 2011): Clã, Adhocracia, Hierarquia e Mercado. (Figura 1). A cultura organizacional será então, com base neste modelo, avaliada segundo um conjunto específico de indicadores de efetividade organizacional, e revelada com base em "valores centrais a partir dos quais são feitos os julgamentos sobre a organização" (CAMERON; QUINN, 1999, p.31).

Figura 1: Competing Values Framework

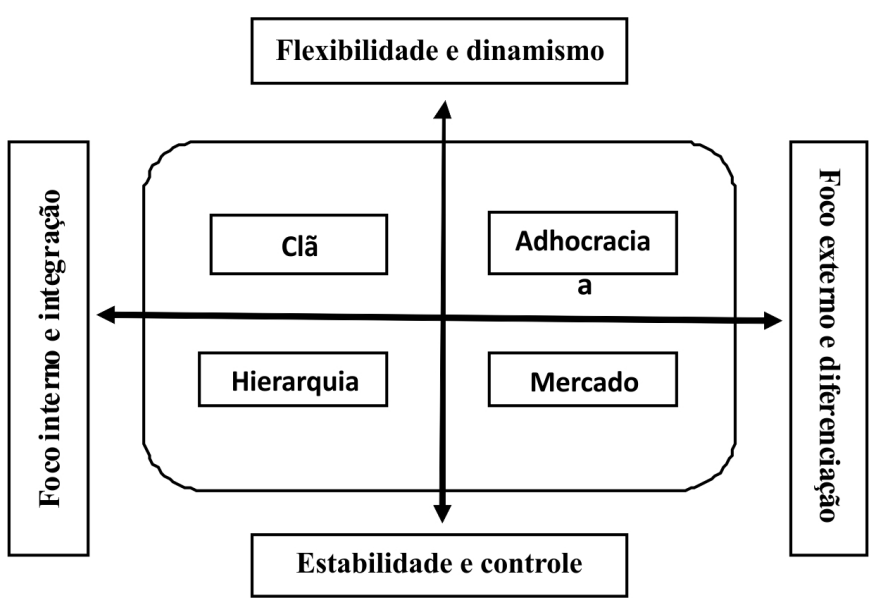

Fonte: Cameron e Quinn (1999, 2006, 2011). 
A Cultura Clã tem como principal característica a flexibilidade e o seu foco é interno, ou seja, enfatiza os fatores e elementos que sustentam a dinâmica interna da organização. Nesse sentido, o pressuposto da cultura Clã é que o trabalho em equipe (ou as equipes de trabalho) é a melhor forma de se alcançar efetividade e os bons resultados organizacionais. Os stakeholders são vistos como parceiros da organização, onde se busca desenvolver ambientes favoráveis às interações humanas e à satisfação dos membros. O papel do líder, então, é promover a participação, o comprometimento e a lealdade no contexto organizacional.

A Adhocracia, por sua vez, é uma tipologia cultural cujo foco é o externo, ou seja, a organização atua conforme as demandas do ambiente e, sendo assim, pressupõe a flexibilidade, o dinamismo, a criatividade e o empreendedorismo como orientações de seu funcionamento. Busca, ainda, inovar em seus processos e nos produtos e serviços. Valoriza o pioneirismo da liderança, que tem perfil visionário e orientado ao risco.

Já a cultura de Hierarquia enfatiza a dimensão interna da organização, caracterizando-se por um ambiente de trabalho formal e estruturado em diversos níveis hierárquicos. Este tipo cultural se sustenta em valores baseados na estabilidade, previsibilidade e eficiência de longo prazo e, para tanto, suas regras, procedimentos, tarefas e funções são, em geral, integradas e estáveis. Em relação à liderança, seu papel é de coordenação, organização e monitoramento.

Por fim, o Mercado é um tipo cultural em que as organizações apresentam orientação externa e mantêm o foco nos resultados e na produtividade, priorizando o atendimento às demandas do mercado competitivo. Essa cultura reconhece o ambiente externo como hostil e com consumidores exigentes. Nessa perspectiva, o papel da liderança volta-se para a consecução dos objetivos organizacionais que se materializam na efetividade baseada em lucro.

Vale ressaltar, que esse arcabouço conceitual e metodológico de avaliação da cultura organizacional, assim como as características de cada quadrante e as respectivas denominações, não foram elaborados aleatoriamente por Cameron e Quinn (1999, 2006, 2011), mas com base em suas próprias pesquisas e em estudos seminais e preditivos do tema encontrados na literatura. Para os efeitos deste artigo, o CVF foi abordado como o modelo de referência dos estudos que vinculam a dimensão cultural à inovação por apresentar-se como predominante nos resultados do levantamento bibliométrico e da revisão sistemática de literatura, que constituíram as estratégias de pesquisa deste trabalho e que são apresentadas na próxima seção.

\section{Procedimentos Metodológicos}

O presente trabalho faz parte de um projeto de pesquisa chamado - Núcleo de Apoio à Gestão da Inovação - NAGI. O projeto NAGI tem como objetivo geral "consolidar e ampliar as ações do núcleo integrado de gestão da inovação, por meio de uma rede de parceiros, através da metodologia NUGIN, para 40 empresas do estado de Santa Catarina. Os autores do presente artigo fazem parte da equipe de uma das instituições envolvidas no projeto, e tem como meta física, a pesquisa e o desenvolvimento de ferramentas de apoio ao processo de inovação. Para isso serão realizadas: pesquisas bibliográficas, concepção de metodologias e ferramentas para a criação de ambientes de inovação, validação e aplicação das metodologias nas empresas. O presente artigo faz parte da primeira parte do projeto, a pesquisa bibliográfica, que segue uma abordagem qualitativa, partindo das orientações de Taylor e Bogdan (1997). No entendimento destes autores, os métodos de investigação em pesquisas qualitativas partem do princípio que existem três etapas: Pré-Campo, Campo e Pós-Campo. Neste artigo será apresentada somente o Pré-Campo, a pesquisa encontrar-se ainda nesta estapa.

Figura 2: Etapas da pesquisa

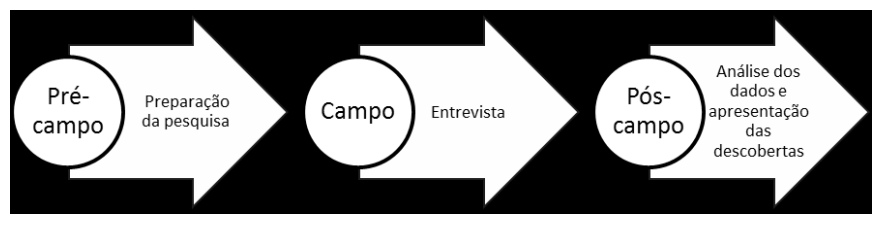

Fonte: os autores

Taylor e Bogdan (1997) caracterizam a etapa de PréCampo como o momento de preparação da pesquisa. Com este entendimento, os autores do artigo definiram as seguintes atividades para sistematizar esta etapa da pesquisa: 
a) Criação do protocolo geral de condução da pesquisa - com a finalidade de orientar a condução de todo o processo da pesquisa;

b) Composição do corpus biliográfico, por meio de buscas exploratórias e sistemáticas - com a finalidade de alicerçar o tema principal da pesquisa e também dar suporte as etpas seguintes da pesquisa.

Quanto a criação do protocolo geral de condução da pesquisa, foi definido que:

1) A pesquisa terá fundamentação em pesquisas bibliográficas na literatura;
2) Entrevistas com especialistas;
3) Visitas de acompanhamento às empresas;
4) Análise dos dados;
5) Apresentação das descobertas realizadas;

Com relação a composição do corpus bibliográfico foi definido que para o cumprimento do objetivo principal de caracterizar o estado da arte na produção acadêmica que articula os temas inovação e cultura organizacional sob um enfoque prescritivo, construiu-se um portfólio de artigos por meio da revisão sistemática de literatura. Este portfólio foi objeto de uma análise quantitativa para a qual se adotou a bibliometria como técnica principal.

Spinak (1998) explica que técnicas como a revisão sistemática e a bibliometria, quando utilizadas em conjunto, constituem procedimentos metodológicos relevantes para que o pesquisador evidencie a produção científica em termos de tendências, autoria e produtividade, além de características, gaps e oportunidades de pesquisa em um determinado campo de conhecimento. O emprego da bibliometria vem auxiliando os pesquisadores a entender os motivos da produção sobre determinando tema, o avanço de conhecimento gerado por essa produção e também contribuindo na identificação dos autores e centros de pesquisas mais relevantes para o desenvolvimento do tema de estudo (MORETI; CAMPANARIO, 2009).
No contexto específico desse trabalho, as técnicas mencionadas foram adotadas para apontar qual (ou quais) os modelos, instrumentos e frameworks vêm sendo mais utilizados em pesquisas que articulam os temas inovação e cultura organizacional. Dessa forma, o portfólio foi passando por sucessivas reduções, até se chegar a um conjunto de artigos desenvolvidos a partir de pesquisas que adotaram o instrumento identificado como o mais citado na literatura. Nesta segunda etapa, então, a análise assumiu uma natureza qualitativa e teve o propósito de analisar resultados de estudos que empregaram modelos/instrumentos de pesquisa predominantes na literatura, no sentido de verificar suas contribuições à temática.

$\mathrm{Na}$ sequência será apresentada como foi realizada a coleta e análise dos dados.

\section{Coleta dos Dados}

Nesta etapa da pesquisa realizou-se a coleta dos dados seguindo os seguintes critérios:

$\checkmark$ Realização de uma busca exploratória sobre descritores relacionados a idioma (inglês, espanhol, português); recorte temporal (20042014); e definição do seguinte grupo convergentes de palavras-chave: [cultura organizacional + valores + inovação]; [valores + comportamento + inovação]; [expressões culturais + comportamento + inovação]. Os grupos de palavras-chave originaram-se do resultado de uma revisão sistemática anterior realizada pelos autores sobre o tema "cultura organizacional";

$\checkmark$ Definição das bases de dados para realização da consulta. Como critério partiu-se de ferramentas mais populares, como é o caso da ferramenta Google Schoolar. A fundamentação para utilização dessa ferramenta, está embasada em Creswell (2010, p. 58). Segundo o autor, outras bases de dados, como Google Schoolar ou Google Acadêmico, podem ser consideradas na busca, pois proporcionam links para resumos, artigos relacionados e versões eletrônicas de artigos afiliados a uma biblioteca que você especifique, bem como possibilita a aquisição do texto intergral do artigo que, muitas vezes, não encontra-se disponível em base como Scopus; as buscas também foram realizadas em quatro bases de dados internacionais, nas áreas de Negócios, 
Engenharias, Psicologia e multidisciplinar. A partir desses critérios, optou-se pelas bases SCOPUS, EBSCO, COMPENDEX e WEB of KNOWLEDGE (portal).

Com base nestes critérios, obteve-se inicialmente 1.209 artigos, somando-se todas as expressões de busca. Para organizar a bibliografia e padronizar a seleção dos

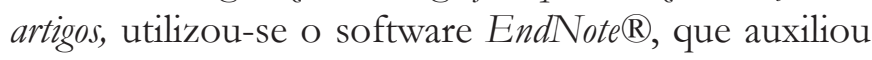
os pesquisadores na realização de algumas funções da pesquisa bibliométrica.

Da aplicação dos filtros de pesquisa resultaram 124 artigos, que foram lidos integralmente. Deste grupo foram extraídos os artigos nos quais constavam padrões ou métodos prescritivos de análise cultura organizacional, inclusive aqueles que propunham o emprego de modelos ou instrumentos. Com a execução deste último critério, os autores formaram o portfólio de 22 artigos, todos com foco em trabalhos prescritivos sobre a cultura organizacional e sua relação com a inovação.

Assim, seguindo todas as etapas referentes aos procedimentos metodológicos adotados neste trabalho, de um portfólio inicial de 1.209 artigos chegou-se a um conjunto de 22 trabalhos que apresentam instrumentos, modelos ou frameworks para analisar, de forma integrada, os temas inovação e cultura organizacional. Deste último conjunto de trabalhos, então, foi identificado o framework mais utilizado pelos estudiosos e, desta forma, foi definido o encaminhamento para responder aos objetivos do estudo.

\section{Análise e Discussão dos Resultados}

Nesta pesquisa buscou-se caracterizar o estado da arte sobre os termos "cultura organizacional" e "inovação", com o objetivo de encontrar na literatura somente trabalhos com foco prescritivo no que diz respeito a modelos, frameworks e instrumentos. Nesse sentido, a revisão sistemática e a análise bibliométrica permitiram sumarizar e documentar as informações relativas a cada um dos 22 artigos que compuseram o portfólio criado, os quais foram analisados por meio da ordenação, estruturação e criação de significado.

\section{Análise geral do portfólio de artigos}

Inicialmente, apresentam-se os dados relativos à quantidade de publicações sobre cada um dos grupos de palavras-chaves encontrados em cada base de dados.

Figura 3: Publicações por termo de busca X Total de publicações por base de dados

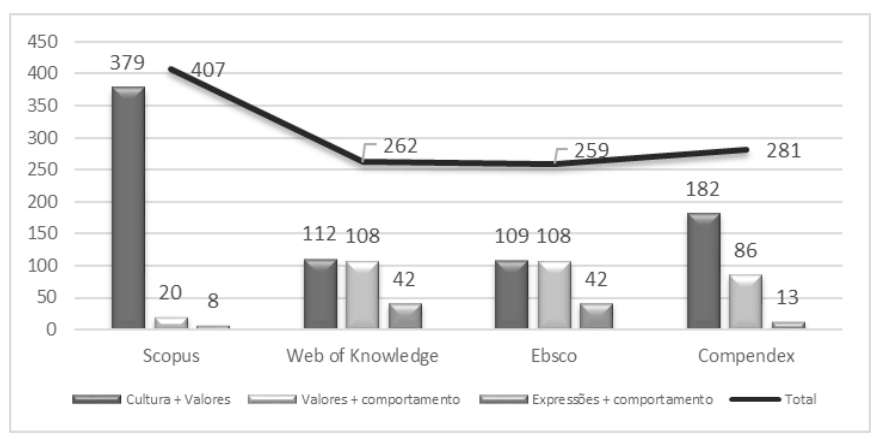

Fonte: dados da pesquisa

$\mathrm{Na}$ Figura 3, destaca-se a importância de todas as bases definidas nos critérios de busca. Os números apresentados no gráfico evidenciam a base de dados SCOPUS como a que teve a maior significância, segundo os critérios definidos para esta pesquisa. Além da busca na referida base retornar a maior quantidade de artigos, ela foi a única que teve todos os seus artigos selecionados para compor o portfólio.

A Figura 3, também destaca o grupo de palavraschave cujo retorno de artigos foi maior: o que reuniu as palavras "cultura, valores e inovação", que resultou em 782 artigos encontrados.

Com foco na verticalização da pesquisa, as figuras, tabelas e análises a seguir tratarão somente dos 22 artigos enquadrados nos objetivos da investigação. Sendo assim, a Figura 4 apresenta a quantificação dos artigos por área e pela tabela de posição (Rank in Category, Q1, Q2, Q3, Q4), que informa a categoria em que o periódico científico pesquisado está incluído. 
Figura 4: Qualificação e área dos artigos analisados

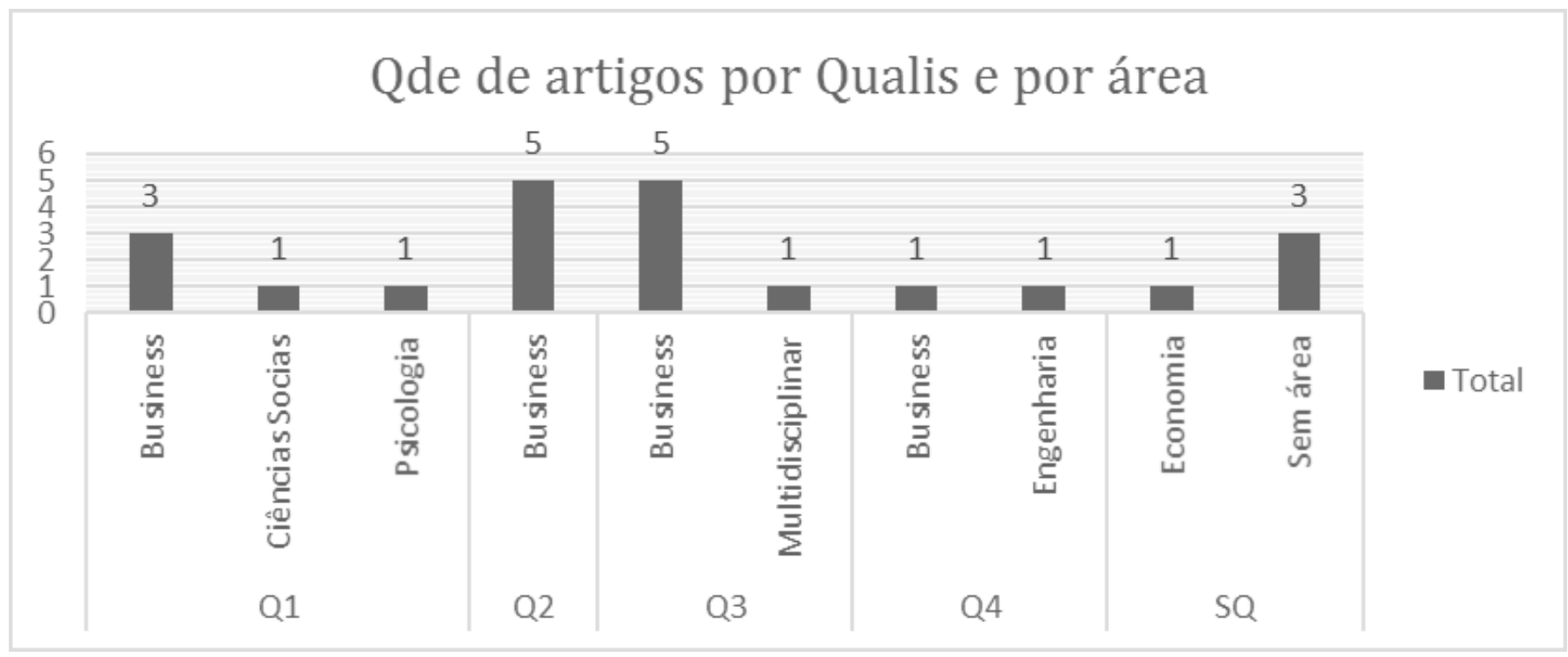

Fonte: dados da pesquisa

Dos 22 artigos que compuseram o portfólio analisado, dez estavam nos quartis Q1 e Q2. Outro ponto a ressaltar é a predominância de periódicos relacionados à área de negócios, o que pode ser explicado pela associação do termo cultura organizacional com inovação.

Outro fator de destaque entre os 22 artigos foi que 50\% dos autores utilizaram a abordagem quantitativa, utilizando o Survey como instrumento de coleta dos dados. A Figura 5 apresenta os detalhes relativos às demais abordagens.

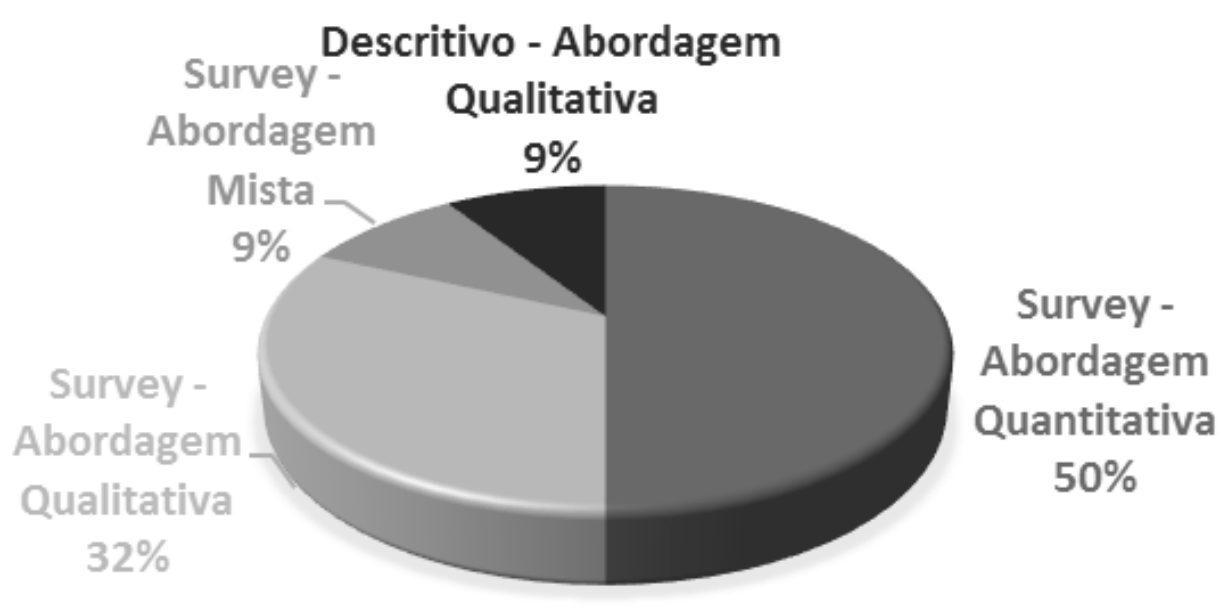

ABORDAGEM DAS PESQUISAS

Fonte: dados da pesquisa 
Dando prosseguimento à análise bibliométrica, partiuse para a categorização dos artigos que se estruturou a partir da criação de três categorias. A primeira delas abrangeu sete artigos que tratam do Competing Values Framework, de Cameron e Quinn (1999, 2006, 2011), empregando o OCAI - Instrumento de Avaliação da Cultura Organizacional - com as suas regras de aplicação. A segunda categoria foi formada por dois artigos que tratam da medição da cultura nas organizações, enfocando exclusivamente a importância de instrumentos para medir, sem abordar algum em específico. E a terceira categoria compreendeu um grupo de treze artigos que tratam de assuntos diversos relacionados à dimensão cultural das organizações, como liderança (4); estereótipos da cultura corporativa (1); fatores chaves (2) e; capacitações para organizações (6).

$\mathrm{Na}$ perspectiva da análise quantitativa realizada sobre o portfólio de artigos levantados, foi possível estabelecer relações de significância entre os termos da busca, identificando de forma sistemática um conjunto de fatores organizacionais relevantes para organizações que têm como objetivo a gestão estratégica da cultura com enfoque em inovação. O Competing Values Framework, proposto por Cameron e Quinn (1999, 2006 2011) para análise de cultura organizacional se apresentou como resultado central frente aos objetivos desta pesquisa, motivo pelo qual os sete artigos do portfólio que o abordam sob a ótica da inovação são analisados a seguir.

\section{Análise especifica: o Competing Values Framework como instrumento de avaliação da cultura organizacional em contextos de inovação}

A partir dos resultados gerais, concentraram-se esforços na análise dos sete artigos que tratavam do Modelo Competing Values Framework (CVF), de Cameron e Quinn (1999, 2006, 2011), com o propósito de verificar as contribuições da aplicação do referido modelo enquanto instrumento de articulação entre inovação e cultura organizacional.

De acordo com a descrição das tipologias culturais no modelo CVF (CAMERON; QUINN, 1999, 2006, 2011) a inovação é uma característica inerente ao tipo de cultura Adhocracia. A análise dos artigos em questão, no que se refere à aplicação do referido modelo, reforça este aspecto e permite ampliar esta abordagem ao constatar que a inovação, em muitos casos, também se encontra associada às culturas que privilegiam a flexibilidade e a orientação externa, onde se verificam os tipos de cultura Clã e Mercado. O quadro 1 sintetiza os principais resultados nesta direção.

Quadro 1: Tipos de cultura identificadas nos estudos e sua relação com a inovação

\begin{tabular}{|l|l|l|l|}
\hline Autoria & Ano & $\begin{array}{l}\text { Tipo de } \\
\text { cultura }\end{array}$ & $\begin{array}{l}\text { Relação com } \\
\text { inovação }\end{array}$ \\
\hline $\begin{array}{l}\text { BUSCHGENS, } \\
\text { BAUSCH e } \\
\text { BALKIN }\end{array}$ & 2013 & $\begin{array}{l}\text { Adhocracia } \\
\text { Mercado } \\
\text { Clã } \\
\text { Hierarquia }\end{array}$ & $\begin{array}{l}\text { Positiva } \\
\text { Positiva } \\
\text { Positiva } \\
\text { Negativa }\end{array}$ \\
\hline $\begin{array}{l}\text { HARTNELL, } \\
\text { OU e } \\
\text { KINICKI }\end{array}$ & 2011 & $\begin{array}{l}\text { Clã } \\
\text { Adhocracia } \\
\text { Mercado }\end{array}$ & $\begin{array}{l}\text { Negativa } \\
\text { Positiva } \\
\text { Positiva }\end{array}$ \\
\hline $\begin{array}{l}\text { JONES, } \\
\text { JIMMIESON e } \\
\text { GRIFFITHS }\end{array}$ & 2005 & Adhocracia & $\begin{array}{l}\text { Positiva (em } \\
\text { relação à } \\
\text { mudança) }\end{array}$ \\
\hline $\begin{array}{l}\text { MOHAMMED } \\
\text { e BARDAI }\end{array}$ & 2012 & $\begin{array}{l}\text { Mercado } \\
\text { Hierarquia }\end{array}$ & $\begin{array}{l}\text { Positiva (com } \\
\text { inovação técnica } \\
\text { Positiva (com } \\
\text { inovação } \\
\text { administrativa) }\end{array}$ \\
\hline $\begin{array}{l}\text { NARANJO- } \\
\text { VALENCIA, } \\
\text { JIMÉNEZ- } \\
\text { JIMÉNEZ e } \\
\text { SANZ-VALLE }\end{array}$ & 2011 & $\begin{array}{l}\text { Adhocracia } \\
\text { Hierarquia }\end{array}$ & $\begin{array}{l}\text { Positiva (com } \\
\text { inovação) } \\
\text { Negativa }\end{array}$ \\
\hline $\begin{array}{l}\text { NARANJO- } \\
\text { VALENCIA, } \\
\text { jIMÉNEZ- } \\
\text { JIMÉNEZ e } \\
\text { SANZ-VALLE }\end{array}$ & 2012 & $\begin{array}{l}\text { Adhocracia com } \\
\text { imitação) }\end{array}$ \\
\hline $\begin{array}{l}\text { Hierarquia } \\
\text { ONEY- } \\
\text { YAZICI, } \\
\text { GIRITLI, } \\
\text { TOPCU- } \\
\text { ORAZ e ACAR }\end{array}$ & 2007 & $\begin{array}{l}\text { Negativa } \\
\text { Hierarquia }\end{array}$ & $\begin{array}{l}\text { Não relaciona } \\
\text { os tipos de } \\
\text { cultura com } \\
\text { inovação }\end{array}$ \\
\hline
\end{tabular}

Fonte: Revisão sistemática da literatura/dados da pesquisa

O estudo de Buschens, Bausch e Balkin (2013) justifica o uso do CVF afirmando que tal modelo permite desenvolver hipóteses sobre as relações entre as variáveis culturais e a inovação. Nesse sentido, os autores testaram e confirmaram a hipótese de que gestores de organizações inovadoras provavelmente implementam uma cultura que enfatiza a flexibilidade 
e a orientação externa, características próprias da cultura do tipo Adhocracia. Ao mesmo tempo, as culturas do tipo Hierárquica, que enfatizam o controle e a orientação interna, são menos suscetíveis de serem encontradas em organizações inovadoras. Os autores acrescentam que a cultura do tipo Clã também pode ser utilizada deliberadamente pelos gestores para promover o foco em inovação nas organizações. Vale a ressalva de que a cultura Hierárquica pode diminuir a capacidade de uma organização para inovar; contudo, isso pode ser interessante para o alcance de outros objetivos organizacionais, reforçando que não existem culturas boas ou más por si próprias. Outro aspecto relacionado e este estudo foi o fato de que as organizações que criam inovações radicais não exibem diferentes culturas organizacionais em relação àquelas que promovem inovações incrementais; logo, não foi possível estabelecer um vínculo entre a cultura organizacional e os tipos de inovação.

Mohammed e Bardai (2012), por sua vez, também buscaram investigar o relacionamento entre os tipos de cultura organizacional e os tipos de inovação, mas, neste caso, considerando a classificação das inovações em técnicas e administrativas. Os resultados da pesquisa apontaram que os quatro tipos de cultura definidos por Cameron e Quinn (1999, 2006, 2011) - Clã, Adhocracia, Mercado e Hierarquia - são preditores significativos para os tipos de inovação organizacional. Contudo, a influência da cultura do tipo Mercado mostrou-se altamente significativa na inovação técnica, o que atesta que a competitividade, o alcance dos objetivos e a superioridade do mercado são importantes variáveis de influência para este tipo de inovação. Também foi constatado que a cultura do tipo Hierarquia apresentou um maior impacto na inovação administrativa, cujo foco é interno, centrado na eficiência e minimização dos custos e caracterizado por estabilidade e confiança. Segundo os autores do artigo, esta é uma área potencialmente difícil para os gestores, visto que a cultura do tipo Hierárquica é menos favorável à inovação de uma maneira geral, no que sugerem medidas de coordenação e organização que permitam a troca de ideias entre funcionários com diferentes origens e formação.

Já Hartnell, Ou e Kinicki (2011) propuseram traçar correlações entre os tipos de cultura (Clã, Adhocracia e Mercado) e os índices de eficácia organizacional (atitudes dos empregados, inovação, qualidade dos produtos e serviços e critérios de eficácia financeira).
Os resultados comprovaram que as culturas de Clã estão fortemente associadas às atitudes positivas dos funcionários e também à qualidade do produto, no entanto apresentaram baixa correlação com a inovação. Os autores sugerem que, embora haja uma expectativa que a cultura do Clã possa promover a inovação, a pesquisa demonstrou que essa correlação pode ser atenuada por processos negativos no grupo. Por outro lado, demonstrou que as culturas de Mercado tanto estão relacionadas aos critérios de eficácia financeira como à inovação. Nesse sentido, reforçam a importância do alinhamento entre as estratégias e a cultura organizacional e o papel da liderança nesse processo, para a obtenção de vantagens competitivas.

Para Naranjo-Valencia, Jiménez-Jiménez e Sanz-Valle (2011) o CVF (CAMERON; QUINN, 1999, 2006, 2011) foi utilizado com o propósito de identificar os tipos de cultura organizacional que promovem ou inibem a inovação organizacional e a estratégia de imitação. Os autores verificaram que a cultura organizacional pode afetar a orientação para inovação ou a imitação, tanto positiva como negativamente. Especificamente, constataram que a cultura do tipo Adhocracia promove uma orientação para a inovação, enquanto a cultura do tipo Hierarquia pode ser associada à imitação. Desta forma, os autores alertam para o fato de que atenção deve ser dada à cultura organizacional quando da definição de estratégias de inovação ou imitação. Ao adotar uma estratégia de imitação é importante promover os valores culturais da Adhocracia, assumindo uma posição de líder no desenvolvimento de produtos, postura empreendedora e a disposição para assumir riscos. Se a estratégia é ser um seguidor, deve-se enfatizar a cultura da Hierarquia, com ênfase na eficiência, entrega confiável, produção de baixo custo, regras e políticas formais além de hierarquia e controle.

Em estudo posterior, Naranjo-Valencia, JiménezJiménez e Sanz-Valle (2012) buscaram aprofundar o estudo sobre os distintos efeitos que as diferentes culturas organizacionais exercem sobre a inovação. Partindo da constatação de que a cultura dos tipos Adhocracia e Hierarquia afetam a inovação de forma positiva e negativa respectivamente, sinalizam que a relação entre a cultura e a inovação é mais complexa do que a literatura apresenta. Nesse sentido, buscam respostas nas características de cada tipo de cultura para verificar seu efeito sobre a inovação e constatam que a característica que mais incide sobre 
a inovação, tanto positiva como negativamente, é o "vínculo organizacional", que faz referência aos valores compartilhados pelas pessoas. Já as outras duas características analisadas em seu estudo, as "características dominantes", que expressam a concepção geral da empresa; os "critérios de êxito", que definem o sucesso da empresa, incidem positivamente sobre a inovação, independentemente do tipo de cultura predominante. Ainda, a característica "gestão dos empregados" não se mostra significativa para nenhuma das culturas estudadas.

A pesquisa desenvolvida por Jones, Jimmieson e Griffiths (2005) utiliza o CVF como instrumento de análise, porém faz uma correlação com a prontidão para a mudança e não com a inovação, que é tratada como uma característica da cultura do tipo Adhocracia, a que os autores denominam sistemas abertos. A natureza dinâmica e inovadora da cultura de sistemas abertos sugere que os empregados percebam sua cultura organizacional como um sistema aberto e estejam mais propensos a ter atitudes positivas em relação à mudança organizacional.

Por fim, Oney-Yazici, Giritli, Topcu-Oraz e Acar (2007) empreendem uma análise sobre o perfil cultural das organizações de construção dentro do contexto da indústria da construção civil na Turquia. Apesar de a pesquisa fazer parte de um projeto mais amplo que investiga a inovação na construção civil, os autores não fazem correlações entre os tipos de cultura e a inovação. Neste caso, o $C V F$ foi utilizado como instrumento para a identificação do tipo de cultura predominante que apontou para um misto de características entre a cultura do tipo Clã e a cultura do tipo Hierárquica, que os autores consideram não corresponder às demandas do ambiente competitivo do setor estudado.

\section{Considerações finais}

A cultura organizacional configura-se em importante vetor para a inovação que se manifesta por meio das interações construídas entre os membros dos diferentes grupos que compõem a organização. São os comportamentos moldados pela cultura organizacional que vão criar condições para que se estabeleça um ambiente propício ou não à inovação, razão pela qual se torna importante destinar atenção ao seu gerenciamento. Neste sentido, buscou-se um respaldo na literatura que articula inovação e cultura organizacional, sob o enfoque prescritivo, visando caracterizar abordagens ou propostas de gerenciamento da cultura com vistas à inovação.

Por meio da revisão sistemática de literatura foi possível identificar, num primeiro momento, um portfólio qualificado de 22 artigos associados à área temática de negócios. Também verificou-se que sete deles tratavam do Competing Values Framework (CVF), de Cameron e Quinn (2006). Considerando o uso significativo do modelo CFV, optou-se por aprofundar qualitativamente a análise dos sete artigos.

Em um segundo momento, buscou-se identificar a relação entre o tipo de cultura proposta pelo modelo $C V F$ e a inovação, uma vez que tal modelo aponta a inovação como uma característica inerente ao tipo de cultura Adhocracia. Foi observado que este aspecto se revela verdadeiro; no entanto, foi possível constatar também que a inovação, em muitos casos, encontra-se associada às culturas que privilegiam a flexibilidade e a orientação externa, onde se verificam características de cultura Clã e Mercado.

De acordo com os estudos de Buschens, Bausch e Balkin (2013) e Naranjo-Valencia, Jiménez-Jiménez e Sanz-Valle $(2011,2012)$, a cultura do tipo Adhocracia promove uma orientação direta para a inovação. Já a pesquisa de Mohammed e Bardai (2012) atestou que a cultura do tipo Mercado mostrou-se altamente significativa nos casos de inovação técnica; na mesma direção, Hartnell, Ou e Kinicki (2011) também identificaram que as culturas de Mercado estão relacionadas à inovação. Por outro lado, os estudos de Mohammed e Bardai (2012) associam a cultura do tipo Hierarquia à inovação administrativa, enquanto Naranjo-Valencia, Jiménez-Jiménez e Sanz-Valle $(2011,2012)$ verificaram que este tipo de cultura pode ser associado à imitação. Sobre a cultura do tipo Clã, Buschens, Bausch e Balkin (2013) consideram que esta pode promover o foco em inovação nas organizações, enquanto Hartnell, Ou e Kinicki (2011) encontraram baixa correlação deste tipo cultural com a inovação.

Por fim, pode-se afirmar que a revisão sistemática de literatura e o estudo bibliométrico, adotados como metodologia de pesquisa deste trabalho, mostraramse adequados à caracterização do estado da arte, no caso em questão, da produção acadêmica que articula os temas inovação e cultura organizacional, pois ajudaram, significativamente, a alicerçar o tema 
principal da pesquisa e também dar suporte as etapas de campo e pós-campo.

Como pesquisas futuras, sugere-se:

a) A investigação do uso do modelo CVF em abordagens qualitativas com o intuito de identificar proposições a serem testadas, uma vez que todos os resultados dos artigos analisados são conclusões da implementação de pesquisas sob a abordagem quantitativa;

b) $\quad \mathrm{Na}$ etapa de campo da atual pesquisa, realizar o estudo e aplicação do Competing Values Framework, principalmente, com enfoque nas dimensões de análise definidas no OCAI;

c) Reflexão e apresentação dos resultados buscando identificar e desenvolver temas e proposições, codificar os dados que sustentem as proposições e, por fim, realizar a interpretação dos dados que foram coletados.

\section{Referências}

ABDULLAH, M.; HAMID, M. R. A.; MUSTAFA, Z.; IDRIS, F.; SURADI, N. R. M. Mediating effect of organisational culture between leadership values on innovation: A partial least squares (PLS) path-modeling. Jurnal Teknologi (Sciences and Engineering), 63(2), 101-106, 2013.

ASMAWI, A.; MOHAN, A. V. Understanding Patterns of Organizational Culture: A Study in Malaysian R\&D Institutions. Proceedings of the 5th IEEE International Conference on Management of Innovation and Technology, (ICMIT2011) Singapore, page 324 - 329, 2011.

BARBOSA, L. (Coord) Cultura e diferença nas organizações: reflexões sobre nós e os outros. Ed. Atlas, São Paulo, 2009.

BIRKINSHAW, J.; HAMEL, G.; MOL, M. J. Management innovation. Academy of Management Review, 33(4), 825-845, 2008.

BUSCHGENS, T.; BAUSCH, A.; BALKIN, D. B. Organizational culture and innovation: A metaanalytic review. Journal of Product Innovation
Management, 30(4), 763-781, 2013.

CAMERON, K.; QUINN, R. Diagnosing and hanging organizational culture: Based on the competing values framework. Ed. Addison-Wesley, Reading, 1999.

CAMERON, K.; QUINN, R. Diagnosing and changing organizational culture: Based on the Competing Values Framework. 2nd ed. San Francisco. CA. The Jossey-Bass business \& management series, 2006

CAMERON, K.; QUINN, R. Diagnosing and changing organizational culture: Based On The Competing Values Framework. 3rd ed. San Francisco. CA. The Jossey-Bass business \& management series, 2011.

CHESBROUGH, H. Open Innovation: the new imperative for creating and profiting from technology. Boston: Harvard Business School, 2003.

CRESWELL, J. W. Projeto de pesquisa métodos qualitativo, quantitativo e misto. In: Projeto de pesquisa métodos qualitativo, quantitativo e misto. Artmed, 2010.

CROSSAN, M. M.; APAYDIN, M. A multidimensional framework of organizational innovation: A systematic review of the literature. Journal of Management Studies, 47(6), 1154-1191, 2010.

DAMANPOUR, F. SCHENIDER, M. Phases of adoption of innovation in organizations. Effects of environment, organization and top managers. British Journal of Management, 17, 215-236, 2006.

DOBNI, C. B. Measuring innovation culture in organizations: The development of a generalized innovation culture construct using exploratory factor analysis. European Journal of Innovation Management, 11(4), 539-559, 2008.

EDQUIST, C. Systems of innovation: technologies, institutions and organizations. London: Pinter, 2007.

EDQUIST, C. Systems of innovation: perspectives and challenges. In: Fagerberg, J., Mowery, D. C.; Nelson, R.R. The Oxford handbook of innovation. New York: Oxford University Press, p.181-208, 2007.

ETZKOWITZ, H. The triple helix: science, technology and the entrepreneurial spirit. Journal of Knowledge-based Innovation in China, 3 (2), 7690, 2011. 
HARTNELL, C. A., OU, A. Y.; KINICKI, A. Organizational culture and organizational Effectiveness: A meta-analytic investigation of the competing values framework's theoretical suppositions. Journal of Applied Psychology, 96(4), 677-694, 2011.

ISAKSEN, S.; TIDD, J. Meeting the Innovation Challenge: Leadership for transformation and growth. Hoboken, USA, John Wiley \& Sons, Ltda, 2006.

JONES, R. A.; JIMMIESON, N. L.; GRIFFITHS, A. The impact of organizational culture and reshaping capabilities on change implementation success: The mediating role of readiness for change. Journal of Management Studies, 42(2), 361-386, 2005.

MOHAMMED, F. A.; BARDAI, B. The role of organizational culture in organizational innovation in higher education institutions - a study of Libyan public universities. Australian Journal of Basic and Applied Sciences, 6(5), 175-184, 2012.

MORETTTI, S. L. A.; CAMPANARIO, M. A. A produção intelectual brasileira em responsabilidade social empresarial - RSE sob a ótica da bibliometria. Revista de Administração Contemporânea, (13), 68-86, 2009.

NACINOVIC, I.; GALETIC, L.; CAVLEK, N. Corporate culture and innovation: implications for reward systems. World Academy of Science, Engineering and Technology, v. 53, p. 397-402, 2009.

NARANJO-VALENCIA， J. C.; JIMENEZJIMENEZ, D.; SANZ-VALLE, R. Innovation or imitation? The role of organizational culture. Management Decision, 49(1), 55-72, 2011.

NARANJO-VALENCIA， J. C.; JIMENEZ JIMENEZ, D.; SANZ-VALLE, R. Is organizational culture an antecedent of firm's innovation? Es la cultura organizativa un determinante de La innovacion en la empresa? Journal of Hydraulic Engineering, 138(9), 63-72, 2012.

NYBAKK, E.; JENSSEN, J. I. Innovation strategy, working climate and financial performance in tradicional manufacturing firms: an empirical analysis. International Journal of Innovation Management. 16(2), April, 2012.

ONEY-YAZICI, E.; GIRITLI, H.; TOPCU-ORAZ,
G.; ACAR, E. Organizational culture: The case of Turkish construction industry. Engineering, Construction and Architectural Management, 14(6), 519-531, 2007.

PETTIGREW, A. M. On studying organizational cultures. Administrative Science Quarterly, 24(4), 570-581, 1979.

SCHEIN, E. H. Cultura organizacional e liderança. São Paulo: Atlas, 2009.

SMIRCICH, L. Concepts of Culture and Organizational Analysis. Administrative Science Quarterly, 28(3): 339-358, 1983.

SMITH, M. et al. Factors influencing an organisation's ability to manage innovation: a structured literature review and conceptual model. International Journal of innovation management, v. 12, n. 04, p. 655-676, 2008.

SPINAK, E. Cienciometricos. Ci. Inf, v. 27, n. 2, p. 141-148, 1998.

TAYLOR, S.; BOGDAN, R. Introduction to research methods. New York: Wiley, 1997.

TETHER, B. S. Who cooperates for innovation and why. An empirical analysis. Research Policy, 31, p. 947-967, 2002.

TIDD, J.; BESSANT, J.; PAVITT, K. Gestão da Inovação. 3. Ed. - Porto Alegre: Bookman, 2008.

TSENG, S. M. The correlation between organizational culture and knowledge conversion on corporate performance", Journal of Knowledge Management, Vol. 14 n.2, p.269-284, 2010.

VAN DE VEN, A. H.; ANGLE, H. L.; POOLE, M. S. Research on the management of innovation: the Minnesota studies. New York: Oxford University Press, 2000.

XERRI, M. J. BRUNETTO W. The impact of the perceived usefulness of worlplace social networks upon the innovative behaviour of the SME employees: a social capital perspective. International Journal of Innovation Management, 15 (5), 959-987, 2011. 